\title{
QUALIDADE E VALOR NUTRITIVO DA SILAGEM DE TRÊS CULTIVARES DE MILHETO ${ }^{1}$
}

\author{
Nutritive quality of silage of three millet cultivars
}

\author{
Pedro Nelson Cesar do Amaral², Antônio Ricardo Evangelista ${ }^{3}$, Flávio Moreno Salvador $^{4}$, José Cardoso Pinto ${ }^{3}$
}

\begin{abstract}
RESUMO
Com o objetivo de determinar o valor nutritivo da silagem de milheto [Pennisetum glaucum (L.) R. Brown], conduziu-se um experimento, nas dependências do Departamento de Zootecnia da UFLA, utilizando o milheto estabelecido em um Latossolo Vermelho Distroférrico típico textura muito argilosa. Os tratamentos constituíram-se de três cultivares (BRS 1501, BN 1 e Comum) e três idades de corte, 70, 90 e 110 dias, para silagem, semeados em novembro/2003. O delineamento experimental utilizado foi o de blocos ao acaso, constituindo-se em fatorial com 3 x 3 ( 3 cultivares x 3 idades de corte), com 3 repetições. Foram avaliados os teores de MS, $\mathrm{PB}, \mathrm{pH}, \mathrm{N}_{-} \mathrm{NH}_{3}(\% \mathrm{~N}$ total), FDN e FDA. Para as silagens, houve diferenças significativas entre as idades de corte para os teores de MS, PB, nitrogênio amoniacal e pH, variando de 21,34 a 36,83\%, 7,13 a 9,50\%, 1,21 a 1,38\% e 3,48 a 3,77, respectivamente. Para a produção de silagem de milheto, o cultivar BN 1 semeado em novembro deve ser colhido aos 90 dias de idade, por ter superado os demais cultivares em composição bromatológica.
\end{abstract}

Termos de indexação: Composição bromatológica, idade de corte, Pennisetum glaucum.

\section{ABSTRACT}

With the aim of evaluating the nutritive value of millet silage [Pennisetum glaucum (L.) R. Brown], an experiment was carried out in the dependencies of the Animal Science Department of UFLA, using the millet established on a Typical Very Clay Texture Distroferric Red Latosol. The treatments consisted of three cultivars (BRS 1501, BN 1 and Comum) and three cutting ages, 70, 90 and 110 days for silage, sown in November/2003. The experimental outline used was the one of randomized blocks, constituting into a factorial with $3 \times 3$ ( 3 cultivars $\times 3$ cutting ages) with three replications. For the silages, there were significant differences among cutting ages for the contents of $\mathrm{DM}, \mathrm{CP}, \mathrm{N}-\mathrm{NH}_{3}$ and $\mathrm{pH}$, varying from 21.34 to $36.83 \%, 7.13$ to $9.50 \%, 1.21$ to $1.38 \%$ and 3.48 to 3.77 , respectively. For the production of millet silage, the cultivar BN 1 planted in November can be harvested at 90 days of age, for overcoming the others in bromathological composition.

Index terms: Bromathological composition, cutting ages, Pennisetum glaucum.

(Recebido em 9 de março de 2006 e aprovado em 14 de março de 2007)

\section{INTRODUÇÃO}

A produção das plantas forrageiras nos trópicos, particularmente no Brasil Central, é caracterizada por períodos em que ocorre produção forrageira elevada quantitativamente e qualitativamente superior, e também por períodos com volumes de produção menores e de qualidade inferior. Essa ocorrência é decorrente da diminuição da disponibilidade de luz, da temperatura e dos índices pluviométricos em determinado período do ano. Essas ocorrências são responsáveis pelos baixos índices de produtividade da pecuária nacional, pois ocorre o impedimento do crescimento da forragem de forma uniforme, ao longo do ano. Na escolha de alternativas, visando minimizar os efeitos da estacionalidade de produção das forrageiras, deve ser levado em conta o nível de exploração pecuária. É nesse sentido que a técnica de conservação de forragens tem sido adotada como estratégia para suprir a escassez de volumoso durante este período crítico do ano. Entre as várias espécies forrageiras que podem ser utilizadas pelos produtores, o milheto [Pennisetum glaucum (L.) R. Brown] vem sendo explorado como alternativa para esse período por apresentar características agronômicas de maior resistência à seca, adaptação a solos de baixa fertilidade, crescimento rápido e boa produção de massa. Pode ser utilizado em plantios de fim de verão e princípio de outono e é considerado

\footnotetext{
${ }^{1}$ Parte da tese apresentada na Universidade Federal de Lavras/UFLA pelo primeiro autor.

${ }^{2}$ Doutor em Zootecnia - Universidade Estadual do Mato Grosso do Sul/UEMS - Campus de Aquidauana - Rodovia Aquidauana/UEMS, Km 12 - $79200-000$ Aquidauana, MS - pnelson@uems.br

${ }^{3}$ Doutores, Professores Titular - Departamento de Zootecnia/DZO - Universidade Federal de Lavras/UFLA - Cx. P. 3037 - $37200-000$ - Lavras, MG aricardo@ufla.br; josecard@ufla.br

${ }^{4}$ Doutor em Nutrição de Ruminantes - Departamento de Zootecnia/DZO - Universidade Federal de Lavras/UFLA - Cx. P. 3037 - $37200-000$ - Lavras, MG morenoflavio@yahoo.com.br
} 
como cultura com grande potencial para a utilização em plantios de sucessão.

O milheto é uma espécie de duplo propósito, cujos grãos são usados para consumo humano e animal; a planta inteira é utilizada como alimento para o gado, na forma de capineira, silagem ou pastejo direto, pois produz grande quantidade de folhagem tenra, nutritiva (até $24 \%$ de PB e digestibilidade variando entre 60 a $78 \%$ ), além de ser palatável e atóxica (MINOCHA, 1991).

Jaster et al. (1985), citados por Andrews \& Dumar (1992), verificaram que novilhas consumindo silagem de sorgo e milheto apresentaram mais alta ingestão e digestibilidade da MS do que aquelas que consumiram silagens de forrageiras de clima temperado. Messman et al. (1992) avaliaram a produção de leite, digestibilidade e fermentação ruminal de vacas no terço médio da lactação recebendo como volumosos a silagem de milheto $(50 \%$ da MS total) ou silagem de milho ou alfafa e verificaram que o consumo de MS, a produção de leite e a digestibilidade não foram influenciados pelos tratamentos. Pelos resultados encontrados, os autores concluíram que a silagem de milheto pode ser considerada como alternativa importante de volumoso para alimentação de ruminantes, mesmo de animais mais exigentes como vacas em lactação.

Em função de suas características agronômicas, o milheto possui bom potencial, podendo ser usado na forma de silagem (LIMA et al., 1999). Vários fatores contribuem para a obtenção de silagem com boa qualidade, entre eles o teor de MS, que deve situar-se entre $28,0 \%$ e $35,0 \%$, para favorecer uma boa fermentação (ANDRIGUETTO et al., 1983).

$\mathrm{Na}$ silagem, teores de nitrogênio amoniacal inferiores a $10 \%$ do nitrogênio total indicam que o processo fermentativo não resultou em quebra excessiva da proteína em amônia (SOEST, 1994).

Araújo et al. (2000), trabalhando com três cultivares de milheto, observaram que as porcentagens de nitrogênio amoniacal variaram de 3,32 a 9,01\%, classificando as silagens como bem preservadas.

Segundo Scaléa (1999), entre os cultivares de milheto existentes destacam-se: Comum ou Italiano, BN 1, BN 2, BRS 1501, CMS 1, CMS 2 entre outras.

Objetivou-se, no presente trabalho, estudar três cultivares comerciais de milheto indicadas para silagem em razão da alta produção de forragem. Os parâmetros estudados foram as características bromatológicas e os aspectos fermentativos, quando ensilados em diferentes idades de corte.

\section{MATERIAL E MÉTODOS}

O experimento foi conduzido em área do Departamento de Zootecnia da Universidade Federal de Lavras (UFLA), situada no município de Lavras - MG, a 918 m de altitude. Segundo a classificação internacional de Köppen, o clima da região é do tipo Cwa, subtropical com verão quente e chuvoso e inverno frio e seco, caracterizado por um total de $23,4 \mathrm{~mm}$ de chuvas no mês mais seco e $295,8 \mathrm{~mm}$ no mês mais chuvoso, com precipitação total anual de $1.529,7 \mathrm{~mm}$ e temperaturas média e mínima iguais a 22,1 e $15,8^{\circ} \mathrm{C}$, respectivamente. A área experimental situa-se em uma meia encosta de uma vertente de topografia ondulada (declividade entre 12 a 18\%), cuja classificação pedológica é um Latossolo Vermelho Distroférrico típico textura muito argilosa.

Segundo as análises de solo, não houve necessidade da utilização de calcário e na adubação de semeadura, realizada em novembro de 2003, foram utilizados $80 \mathrm{~kg} / \mathrm{ha}$ de $\mathrm{P}_{2} \mathrm{O}_{5}$ (444 kg de superfosfato simples), $60 \mathrm{~kg} /$ ha de $\mathrm{K}_{2} \mathrm{O}$ (103 kg de cloreto de potássio) e $20 \mathrm{~kg} / \mathrm{ha}$ de $\mathrm{N}$ (100 kg de sulfato de amônio). Também foi efetuada a adubação de cobertura, com $100 \mathrm{~kg} / \mathrm{ha}$ de N (500 kg de sulfato de amônio), aplicados 30 dias após a emergência.

Foram avaliados os cultivares BRS 1501, BN 1 e CMS 01 (Comum) e efetuados cortes em três idades (70, 90 e 110 dias após a semeadura), compondo um total de nove tratamentos, em esquema fatorial $3 \times 3$ (três cultivares e três idades de corte), dispostos de acordo com um delineamento em blocos casualisados, com três repetições por tratamento, sendo que nas parcelas foram alocados os cultivares. Nas parcelas foram alocados os cultivares, semeados em cinco linhas de $5 \mathrm{~m}$ de comprimento, espaçadas de $0,70 \mathrm{~m}$ entre- linhas, perfazendo uma área total de $17,50 \mathrm{~m}^{2}$. Foram consideradas como bordaduras as duas linhas externas e $0,50 \mathrm{~m}$ nas extremidades, resultando em $8,4 \mathrm{~m}^{2}$ de área útil e $9,1 \mathrm{~m}^{2}$ de área de bordadura.

Nas épocas pré-determinadas, as plantas da área útil de cada parcela foram cortadas manualmente com cutelo, a uma altura de $5 \mathrm{~cm}$ do solo, sendo retirada de cada uma delas um (01) kg de amostra, que foi acondicionada em saco apropriado para realização de présecagem, em estufa de ventilação forçada a $65^{\circ} \mathrm{C}$ por 72 horas. Posteriormente, as amostras foram pesadas, moídas e armazenadas em recipientes plásticos adequados até a realização das análises laboratoriais.

Parte do material colhido foi destinado à produção de silagem, sendo picado em partículas entre 1,0 e 2,0 cm, com um desintegrador estacionário. Após homogeneização do material picado, parte foi armazenado em silos 
experimentais de "PVC", medindo $10 \mathrm{~cm}$ de diâmetro e 40 $\mathrm{cm}$ de comprimento. $\mathrm{O}$ material ensilado foi compactado com pêndulo de ferro e os silos foram fechados com tampas de "PVC", uma delas dotada de válvula tipo "Bunsen", sendo, em seguida, lacrados com fita adesiva. Depois de fechados, foram colocados na posição inclinada, visando facilitar a saída de efluentes pela válvula de "Bunsen", simulando um silo-trincheira.

Transcorridos 50 dias, os silos experimentais foram abertos, descartando-se as porções superior e inferior de cada um. A porção central do silo foi homogeneizada, amostrada, sendo que metade das amostras desse material foi congelada e a outra metade foi pesada em sacos de papel e levada para estufa de ventilação forçada a $60-65^{\circ} \mathrm{C}$ durante 72 horas, para a determinação de matéria pré-seca. As amostras pré-secas foram moídas em um moinho do tipo Willey, em peneira com malha de dois milímetros, colocadas em recipientes de polietileno com tampa, identificadas e armazenadas para posteriores análises. No momento em que cada silo experimental foi aberto, parte do material foi prensado em uma prensa hidráulica, para extração do suco da silagem. Parte desse suco, sem nenhum diluição, foi imediatamente empregado na avaliação de $\mathrm{pH}$, utilizando-se um potenciômetro Beckman Expandomatic SS-2 e outra parte, para a determinação do teor de nitrogênio amoniacal como porcentagem do nitrogênio total $\left[\mathrm{N}-\mathrm{NH}_{3}\right.$ (\%Ntotal)] (AOAC, 1990).

As análises bromatológicas foram realizadas no Laboratório de Pesquisa Animal do Departamento de Zootecnia da UFLA, onde foram determinados os teores de matéria seca (MS) e proteína bruta (PB), conforme os métodos recomendados pela AOAC (1990). As determinações de fibra em detergente neutro (FDN) e fibra em detergente ácido (FDA) foram efetuadas conforme metodologias propostas por Soest et al. (1991).

Após coleta e tabulação dos dados, os cultivares foram analisados por meio do Software estatístico SISVAR
- Sistema para análise de variância de dados balanceados (FERREIRA, 2000). Os dados foram submetidos à análise de variância, sendo que, para o fator cultivar, quando significativo, foi aplicado o teste de Scott-Knott, com significância de $5 \%$ de probabilidade.

\section{RESULTADOS E DISCUSSÃO}

Todas as silagens apresentaram odor agradável, coloração verde parda, textura firme e ausência de partes mofadas.

Observam-se, na Tabela 1, os teores de MS das silagens das três cultivares de milheto em três idades de corte, no período das águas. Houve efeito significativo para cultivares e idades de corte $(\mathrm{P}<0,01)$ e para a interação cultivar $\mathrm{x}$ idade $(\mathrm{P}<0,05)$.

Aos 70 dias, a porcentagem de MS variou de 21,57 a $20,87 \%$ entre os cultivares, enquanto aos 110 dias a variação foi entre 32,42 e $42,00 \%$.

As concentrações médias de MS das silagens nas diferentes idades de corte, quando observadas em relação às das forragens que lhes deram origem, mostraram-se as mesmas (Tabela 2) enquanto o esperado seria um aumento no teor de MS. Tais aumentos são normalmente explicados pela liberação de água quando os açúcares são fermentados a ácidos orgânicos (MCDONALD et al., 1991).

Em relação aos teores de MS das silagens de milheto encontram-se diversos valores variando de $32,62 \%$ (CHAVES, 1997); de 22,64 a 24,49\% (ARAÚJO et al., 2000); de 32,04 a 38,23\% (GRISE et al., 2001); de 22,15 a 25,38\% (FIALHO et al., 2003); de 22,89 a 37,23\% (AMARAL, 2003); de 22,83 a 27,90\% (COELHO, 2003). Esses teores de MS das silagens de milheto apresentados, condizem com o que é preconizado pela literatura, situando-se entre 28,0 e 35,0\% (ANDRIGUETTO et al., 1983); entre 30 e 35\% (MUCK, 1988) e um mínimo de 26\% (HAIGH, 1990).

Com relação aos teores de proteína bruta, houve efeito significativo dos cultivares e idades $(\mathrm{P}<0,01)$ que constatam-se pela Tabela 3 .

Tabela 1 - Teores de MS (\%) das silagens de cultivares de milheto, submetidos a três idades de corte no período das “águas”.

\begin{tabular}{ccccc}
\hline \multirow{2}{*}{$\begin{array}{c}\text { Idades de corte } \\
\text { (dias) }\end{array}$} & \multicolumn{3}{c}{ Cultivares } & \multirow{2}{*}{ Média } \\
\cline { 2 - 4 } 70 & BRS 1501 & BN 1 & Comum & $21,34 \mathrm{c}$ \\
90 & $21,57 \mathrm{Ac}$ & $20,87 \mathrm{Ac}$ & $21,57 \mathrm{Ac}$ & $27,69 \mathrm{~b}$ \\
110 & $29,25 \mathrm{Ab}$ & $26,99 \mathrm{Ab}$ & $26,82 \mathrm{Ab}$ & $36,83 \mathrm{a}$ \\
Média & $42,00 \mathrm{Aa}$ & $36,07 \mathrm{Ba}$ & $32,42 \mathrm{Ba}$ & \\
\hline
\end{tabular}

Médias seguidas por letras distintas, maiúsculas na linha e minúsculas na coluna, diferem entre si pelo teste de Scott-Knott $(\mathrm{P}<0,05)$. 
Tabela 2 - Teores médios de matéria seca (silagem e material original) e proteína bruta (material original) de cultivares de milheto (BRS 1501, BN 1 e Comum), submetidos a três idades de cortes no período das “águas".

\begin{tabular}{cccc}
\hline Idades de corte & Silagem & \multicolumn{2}{c}{ Material original } \\
\cline { 3 - 4 }$($ dias $)$ & MS\% & MS\% & PB (\% na MS) \\
\hline 70 & $21,3 \mathrm{c}$ & $21,4 \mathrm{c}$ & $9,86 \mathrm{a}$ \\
90 & $27,7 \mathrm{~b}$ & $27,9 \mathrm{~b}$ & $7,61 \mathrm{~b}$ \\
110 & $36,8 \mathrm{a}$ & $35,4 \mathrm{a}$ & $6,96 \mathrm{~b}$ \\
\hline
\end{tabular}

Médias seguidas por letras distintas minúsculas na coluna, diferem entre si pelo teste de Scott-Knott $(\mathrm{P}<0,05)$.

Tabela 3 - Teores de PB (\% na MS) das silagens de cultivares de milheto, submetidos a três idades de corte no período das "águas".

\begin{tabular}{ccccc}
\hline \multirow{2}{*}{$\begin{array}{c}\text { Idades de corte } \\
\text { (dias) }\end{array}$} & BRS 1501 & Cultivares & Média \\
\cline { 2 - 4 } 70 & $10,68 \mathrm{Aa}$ & $9,31 \mathrm{Ba}$ & Comum & $9,50 \mathrm{a}$ \\
90 & $7,62 \mathrm{Ab}$ & $7,58 \mathrm{Ab}$ & $6,17 \mathrm{Bb}$ & $7,13 \mathrm{c}$ \\
110 & $9,89 \mathrm{Aa}$ & $8,14 \mathrm{Bb}$ & $7,18 \mathrm{Bb}$ & $8,40 \mathrm{~b}$ \\
\hline Média & $9,40 \mathrm{~A}$ & $8,34 \mathrm{~B}$ & $7,28 \mathrm{C}$ & \\
\hline
\end{tabular}

Médias seguidas por letras distintas, maiúsculas na linha e minúsculas na coluna, diferem entre si pelo teste de Scott-Knott $(\mathrm{P}<0,05)$.

Observa-se que houve pequena redução dos valores médios de PB do material original (Tabela 2) comparado aos da silagem, sendo que, no material original, os teores médios de PB foram de $9,86 \%$ aos 70 dias e $7,61 \%$ aos 90 dias de idade, ao passo que, para as silagens, eles foram de $9,50 \%$ e $7,13 \%$, respectivamente (Tabela 3). Esse fato sugere a ocorrência de alguma proteólise durante a fermentação sem, contudo, prejudicar o processo fermentativo. Porém, aos 110 dias de idade o material original apresentava $6,96 \%$, enquanto na silagem, nessa mesma idade, foi registrado teor de $8,40 \%$, demonstrando, nesse caso, efeito de concentração decorrente de perdas por volatilização ou efluentes, embora essas variáveis não tenham sido avaliadas. Segundo Church (1988), um alimento e/ou dieta deve conter pelo menos 7\% de PB para fornecer nitrogênio suficiente para uma efetiva fermentação microbiana no rúmen. Nesse trabalho, todos os cultivares (exceto o cv. Comum, aos 90 dias) forneceram PB suficiente para garantir boa fermentação ruminal.

$\mathrm{Na}$ silagem de milheto, os valores de PB obtidos nesse estudo são semelhantes aos relatados por outros autores, como 9,51\% (CHAVES, 1997); entre 8,89 e 9,45\% (BERGAMASCHINE et al., 1998); entre 9,59 e 11,32\% (ARAÚJO et al., 2000) e entre 10,14 e 8,21\% (AMARAL, 2003), enquanto valores abaixo (entre 5,61 e 6,15\%) também foram relatados por Fialho et al. (2003).
Houve efeito significativo $(\mathrm{P}<0,01)$ da idade sobre os valores de $\mathrm{pH}$ das silagens que tiveram ligeira elevação dos $70(3,48)$ para os 90 dias $(3,62)$ e até 110 dias de idade $(3,77)$ (Tabela 4).

Esse aumento, possivelmente, ocorreu em razão da redução nos teores de $\mathrm{PB}$, dos 70 aos 90 dias e dos 90 até os 110 dias de idade, provavelmente porque maior degradação de proteína e seus consequientes produtos resultantes da degradação (aminoácidos, aminas e amônia) tenham dificultado a queda rápida do $\mathrm{pH}$, sem, no entanto, prejudicar a silagem nessas idades (MCDONALD et al., 1991).

Pode-se observar também, em vários trabalhos, valores de $\mathrm{pH}$ acima dos encontrados neste estudo, oscilando entre 5,4 a 4,1 (SILVEIRA, 1980); 5,08 a 3,56 (ARAÚJO et al., 2000), bem como valores semelhantes aos ora encontrados, como os relatados por Chaves (1997) $(3,22$ a 3,69) e Fialho et al. (2003) $(3,68$ a 3,72).

Não houve diferença $(\mathrm{P}>0,05)$ entre os teores de FDN das silagens, embora tenha sido observada uma variação entre 60,15 e 68,63\%. Esses valores são próximos aos encontrados por Pereira (1991), de 68,5\%; Chaves (1997), de 68,5\%; Guimarães Júnior et al. (2001), de 62,0\%; Fialho et al. (2003), de 59,17 até 67,60\%, e superiores aos obtidos no trabalho de Bergamaschine et al. (1998), entre 48,54 e 62,24\%, da silagem de milheto puro ou com aditivos.

Quanto aos teores de FDA, a diferença entre os cultivares foi significativa $(\mathrm{P}<0,01)$ bem como a interação cultivar $x$ idade $(\mathrm{P}<0,05)($ Tabela 5$)$. 
Os valores de FDA encontrados (Tabela 5) foram semelhantes e maiores que os encontrados por Grise et al. (2001), de 42,50 e 38,32\% na MS da silagem de dois cultivares de milheto sem aditivo; por Guimarães Júnior et al. (2001), iguais a 40,1 36,9 e 38,8\% na MS das silagens de três cultivares de milheto, com média geral de $38,6 \%$; por Fialho et al. (2003), iguais a 43,27 e 38,95 e 41,82 e 40,41\% com adição de sorgo (0 e 5\%) e com e sem aditivos, respectivamente. Valores menores também foram relatados por Bergamaschine et al. (1998), com teores médios de 36,96 e $36,16 \%$ (sem e com inoculantes) e de 41,$19 ; 36,32$ e $32,18 \%$ (aditivadas com resíduo de milho de 0; 5 e 10\%).

McDonald et al. (1991) detectaram que a quantidade de ácidos orgânicos produzidos durante a fermentação da silagem é superior à quantidade possível de ser produzida a partir dos carboidratos solúveis disponíveis no material ensilado, concluindo-se, portanto, que deve existir uma fonte extra de carboidratos. Possivelmente, a hemicelulose é o principal carboidrato hidrolisado, podendo ser quebrada pelas hemicelulases de origem microbiana provenientes da própria planta ou mesmo por ação de ácidos.

Houve efeito significativo dos cultivares e das idades de corte $(\mathrm{P}<0,01)$ e da interação cultivar $\mathrm{x}$ idade $(\mathrm{P}<0,05)$ sobre os valores de nitrogênio amoniacal das silagens de milheto. Os teores de nitrogênio amoniacal/nitrogênio total das silagens são apresentados na Tabela 6 .

Para essa variável, o menor valor foi $0,97 \%$, da silagem do cultivar BRS 1501 aos 110 dias, enquanto para os demais cultivares os valores se mantiveram entre 1,08 a $1,50 \%$, dentro dos limites recomendados por McDonald \& Whittenbury (1973), segundo os quais não devem ultrapassar $12,5 \%$ do $\mathrm{N}$ total. Os valores encontrados neste estudo são menores do que os de Chaves (1997), de 2,96\% da silagem de milheto; de Bergamaschine et al. (1998), variando de 6,43 e 6,11\% (sem e com aditivos) e de 6,37; 6,26 e 6,18\% (com 0; 5 e $10 \%$ de resíduo de milho); e de Araújo et al. (2000), quando ocorreram variações entre 3,32\% (milheto BN 2 no primeiro dia de abertura do silo) e 9,01\% (milheto CMS 02 , no $56^{\circ}$ dia de abertura do silo).

De acordo com Mahanna (1994) e Rotz \& Muck (1994), pode-se classificar as silagens aqui estudadas como de qualidade muito boa em relação ao nitrogênio amoniacal, uma vez que apresentaram, em média, menos de $5 \%$ de N$\mathrm{NH}_{3} \% \mathrm{~N}$ total, que é o valor máximo estabelecido para essa classificação.

Tabela 4 - Valores de pH das silagens de cultivares de milheto, submetidos a três idades de corte no período das "águas".

\begin{tabular}{ccccc}
\hline \multirow{2}{*}{$\begin{array}{c}\text { Idades de corte } \\
\text { (dias) }\end{array}$} & \multicolumn{3}{c}{ Cultivares } & \multirow{2}{*}{ Média } \\
\cline { 2 - 4 } & BRS 1501 & BN 1 & Comum & $3,48 \mathrm{c}$ \\
90 & $3,48 \mathrm{Ab}$ & $3,49 \mathrm{Ab}$ & $3,47 \mathrm{Ab}$ & $3,62 \mathrm{~b}$ \\
110 & $3,59 \mathrm{Ab}$ & $3,61 \mathrm{Ab}$ & $3,64 \mathrm{Ab}$ & $3,77 \mathrm{a}$ \\
\hline Média & $3,87 \mathrm{Aa}$ & $3,76 \mathrm{Aa}$ & $3,68 \mathrm{Aa}$ & $3,59 \mathrm{~A}$ \\
\hline
\end{tabular}

Médias seguidas por letras distintas, maiúsculas na linha e minúsculas na coluna, diferem entre si pelo teste de Scott-Knott $(\mathrm{P}<0,05)$.

Tabela 5 - Teores de FDA (\% na MS) das silagens de cultivares de milheto, submetidos a três idades de corte no período das "águas".

\begin{tabular}{ccccc}
\hline \multirow{2}{*}{$\begin{array}{c}\text { Idades de corte } \\
\text { (dias) }\end{array}$} & BRS 1501 & Cultivares & \multirow{2}{*}{ Média } \\
\cline { 2 - 4 } 70 & $38,43 \mathrm{Aa}$ & $38,71 \mathrm{Aa}$ & Comum & $39,51 \mathrm{a}$ \\
90 & $40,11 \mathrm{Aa}$ & $40,90 \mathrm{Aa}$ & $41,38 \mathrm{Aa}$ & $41,54 \mathrm{a}$ \\
110 & $35,57 \mathrm{Ca}$ & $41,02 \mathrm{Ba}$ & $46,06 \mathrm{Aa} \mathrm{Aa}$ & $40,88 \mathrm{a}$ \\
\hline Média & $38,03 \mathrm{C}$ & $40,21 \mathrm{~B}$ & $43,69 \mathrm{~A}$ & \\
\hline
\end{tabular}

Médias seguidas por letras distintas, maiúsculas na linha e minúsculas na coluna, diferem entre si pelo teste de Scott-Knott $(\mathrm{P}<0,05)$. 
Tabela 6 - Valores de nitrogênio amoniacal/nitrogênio total das silagens de cultivares de milheto, submetidos a três idades de corte no período das "águas".

\begin{tabular}{ccccc}
\hline \multirow{2}{*}{$\begin{array}{c}\text { Idades de corte } \\
\text { (dias) }\end{array}$} & BRS 1501 & Cultivares & Média \\
\cline { 2 - 4 } 70 & $1,50 \mathrm{Aa}$ & $1,45 \mathrm{Aa}$ & Comum & $1,45 \mathrm{a}$ \\
90 & $1,25 \mathrm{Aa}$ & $1,44 \mathrm{Aa}$ & $1,16 \mathrm{Aa}$ & $1,28 \mathrm{a}$ \\
110 & $0,97 \mathrm{Ab}$ & $1,23 \mathrm{Aa}$ & $1,08 \mathrm{Aa}$ & $1,09 \mathrm{~b}$ \\
\hline Média & $1,24 \mathrm{~A}$ & $1,38 \mathrm{~A}$ & $1,21 \mathrm{~A}$ & \\
\hline
\end{tabular}

Médias seguidas por letras distintas, maiúsculas na linha e minúsculas na coluna, diferem entre si pelo teste de Scott-Knott $(\mathrm{P}<0,05)$.

\section{CONCLUSÕES}

Em relação aos valores de MS, obtidas pelas silagens, pode-se concluir que, o cultivar BR 1501, pode ser colhido aos 90 dias, o cultivar BN 1 entre 90 e 110 dias e o cultivar comum, aos 110 dias de idade. Deve-se, também, levar em consideração que o cultivar BN 1 apresentou menor variação no valor nutritivo, mantendo sua qualidade ao longo do período experimental.

\section{REFERÊNCIAS BIBLIOGRÁFICAS}

AMARAL, P. N. C. Silagem e rolão de milheto em diferentes idades de corte. 2003. 78 p. Dissertação (Mestrado em Forragicultura e Pastagens) - Universidade Federal de Lavras, Lavras, 2003.

ANDREWS, D. J.; DUMAR, K. A. Pearl millet for food, feed, and forage. Advances in Agronomy, New York, v. 48, p. 89-139, 1992.

ANDRIGUETTO, J. M.; MINARDI, I.; FLEMMING, J. S.; SOUZA, G. A. Nutrição animal. São Paulo: Nobel, 1983. v. $1,395 \mathrm{p}$.

ARAÚJO, V. L.; RODRIGUES, N. M.; GONÇALVES, L. C.; BORGES, I.; RODRIGUES, J. A. A. S.; BORGES, A. L. C. C.; ALMEIDA, P. M. A.; RIBEIRO, L. G. Qualidade e perfil de fermentação das silagens de três cultivares de milheto. In: REUNIÃ̃O DA SOCIEDADE BRASILEIRA DE ZOOTECNIA, 2000, Viçosa. Anais... Viçosa: UFV, 2000.

ASSOCIATION OF OFFICIAL ANALYTICAL CHEMISTS. Official methods of analysis. 15. ed. Arlington, 1990. v. 1, $1117 \mathrm{p}$.

BERGAMASCHINE, A. F.; GUATURA, A. S.; BASTOS, J. F. P.; MOPRAIS, D. S. Efeito da adição de resíduo de milho e inoculante microbiano na qualidade da silagem de milheto.
In: REUNIÃO ANUAL DA SOCIEDADE BRASILEIRA DE ZOOTECNIA, 35., 1998, Botucatu. Anais... Botucatu: SBZ, 1998. v. 2, p. 287-289.

CHAVES, C. A. dos S. Produção e valor nutritivo das silagens de capim-sudão [Sorghum sudanense (Piper) Stapf], milheto [Pennisetum americanum (L.) Leeke,], teosinto (Euchlaena mexicana Schard) e milho (Zea mays L.). 1997. 56 f. Dissertação (Mestrado em Zootecnia) Universidade Federal de Lavras, Lavras, 1997.

CHURCH, D. C. Fisiología digestiva y nutrición de los rumiantes. Zaragoza: Acriba, 1988. 641 p.

COELHO, E. M. Parâmetros qualitativos da silagem de milheto (Pennisetum americanum). In: REUNIÃO ANUAL DA SOCIEDADE BRASILEIRA DE ZOOTECNIA. 40., 2003, Santa Maria. Anais... Santa Maria: UFSM, 2003.

FERREIRA, D. F. Análises estatísticas por meio do Sisvar para Windons versão 4.3. In: REUNIÃO ANAUAL DA REGIÃO BRASILEIRA DA SOCIEDADE INTERNACIONAL DE BIOMETRIA, 45., 2000, São Carlos. Programas e resumos... São Carlos: UFSCar, 2000. p. 255-258.

FIALHO, M. P.; TRAVAIM, M. F.; DIAS, M.; ROSA, R. B.; REZENDE, L. H. G. S.; ALBERTINI, T. Z.; DETMANN, E.; ÍTAVO, C. C. B. F.; MORAIS, M. G. Avaliação da silagem de milheto (Pennisetum americanum) submetida a diferentes aditivos. In: REUNIÃO ANUAL DA SOCIEDADE BRASILEIRA DE ZOOTECNIA, 2003, Santa Maria. Anais... Santa Maria: UFSM, 2003.

GRISE, M. M.; JOBIM, C. C.; CECATO, U.; GONÇALVES, G. D. Efeito do uso de inoculantes na composição química e $\mathrm{pH}$ da silagem de milheto (Pennisetum americanum (L.) Lekee). In: REUNIÃO DA SOCIEDADE BRASILEIRA DE ZOOTECNIA, 38., 2001, Piracicaba. Anais...Piracicaba: SBZ, 2001. 
GUIMARÃES JÚNIOR, R.; GONÇÁLVES, L.; RODRIGUES, J. A. S. Consumo e digestibilidade aparente da matéria seca e da proteína bruta das silagens de três genótipos de milheto (Pennisetum glaucum) NPM-1, BRS-1501, CMS-3 em ovinos. In: REUNIÃO ANUAL DA SOCIEDADE BRASILEIRA DE ZOOTECNIA, 38., 2001, Piracicaba. Anais... Piracicaba: SBZ, 2001. p. 1096-1097.

HAIGH, P. M. Effect of herbage water-soluble carbohydrate content and weather conditions at ensilage on the fermentation of grass silages made on commercial farms. Grass and Forage Science, Oxford, v. 42, n. 3, p. 279-317, Sept. 1990.

LIMA, M. L. M.; CASTRO, F. G. F.; TAMASSIA, L. F. M Culturas não convencionais: girassol e milheto. In: SIMPÓSIO SOBRE NUTRIÇÃO DE BOVINOS, 7., 1999, Piracicaba. Anais... Piracicaba: FEALQ, 1999. p. 167-195.

MAHANNA, B. Proper management assures high-quality, grains. Feedstuffs, Minneapolis, v. 10, p. 12-56, 1994.

McDONALD, P.; HENDERSON, A. R.; HERON, S. The biochemistry of silage. 2. ed. Marlow: Chalcome, 1991. 340 p.

McDONALD, P.; WHITTENBURY, R. The ensilage process. In: BUTLER, G. W.; BAILEY, R. W. Chemistry and Biochemistry of Herage. London: Academic, 1973. v. 3, p. 33-60.

MESSMAN, M. A.; WEISS, W. P.; HENDERLONG, P. R.; SHOCKEY, W. L. Evaluation of pearl millet and field peas plus triticale silages for midlactation dairy cows. Journal of Dairy Science, Champaign, v. 75, n. 10, p. 2769-2775, Oct. 1992.

MINOCHA, J. L. Pearl millet cytogenics. In: GUPTA, P. K.; TSUCHIVA. Chromossome engineering in plants genetics. Amsterdan: Elsevier, 1991. p. 599-611.
MUCK, R. E. Factors influencing silage quality and their implications for management. Journal of Dairy Science, Champaign, v. 71, n. 11, p. 2992-3002, Nov. 1988.

PEREIRA, O. G. Produtividade do milho (Zea mays L.), do sorgo (Sorghum bicolor (L.) Moench.), da aveia (Avena sativa L.) e do híbrido (S. bicolor $\mathrm{x}$ S. sudanense) e os respectivos valores nutritivos sob a forma de silagem e verde picado. 1991. 86 f. Dissertação (Mestrado em Zootecnia) - Universidade Federal de Viçosa, Viçosa, 1991.

ROTZ, C. A.; MUCK, R. E. Changes in forage quality during harvest and storage. In: NATIONAL CONFERENCE ON FORAGE QUALITY, EVALUATION AND HELD AT THE UNIVERSITY OF NEBRASKA, 1994, Lincoln. Proccedings... Lincoln: University of Nebraska, 1994. p. 828-868

SCALÉA, M. A. A cultura do milheto e seu uso no plantio direto no cerrado. In: WORSHOP INTERNACIONAL DE MILHETO, 1999, Planaltina. Anais... Planaltina: Embrapa Cerrados, 1999. p. 75-82.

SILVEIRA, C. A. M. Efeito de doses de nitrogênio e regimes de corte no rendimento de matéria seca de milheto e sorgo forrageiros e no valor nutritivo da silagem de milheto. 1980. 121 f. Dissertação (Mestrado em Agronomia) Universidade Federal do Rio Grande do Sul, Porto Alegre, 1980.

SOEST, P. J. van. Nutritional ecology of the ruminant. Ithaca: Cornell University, 1994. 476 p.

SOEST, P. J. van; ROBERTSON, J. B.; LEWIS, B. A. Methods for dietary fiber, neutral detergent fiber and nonstarch polysaccharides in relation to animal nutrition. Journal of Dairy Science, Champaign, v. 74, n. 10, p. 35833597, Oct. 1991. 